\title{
Axial interbody arthrodesis of the L5-S1 segment: a systematic review of the literature
}

\author{
Gregory D. Schroeder, MD, Christopher K. Kepler, MD, MBA, and Alexander R. Vaccaro, MD, PhD \\ Rothman Institute, Thomas Jefferson University, Philadelphia, Pennsylvania
}

OBJECT The object of this study was to determine the fusion rate and safety profile of an axial interbody arthrodesis of the L5-S1 motion segment.

METHODS A systematic search of MEDLINE was conducted for literature published between January 1,2000 , and August 17, 2014. All peer-reviewed articles related to the fusion rate of L5-S1 and the safety profile of an axial interbody arthrodesis were evaluated.

RESULTS Seventy-four articles were identified, but only 15 (13 case series and 2 retrospective cohort studies) met the study inclusion criteria. The overall pseudarthrosis rate at L5-S1 was $6.9 \%$, and the rate of all other complications was $12.9 \%$. A total of $14.4 \%$ of patients required additional surgery, and the infection rate was $5.4 \%$. Deformity studies reported a significantly increased rate of complications (46.3\%), and prospectively collected data demonstrated significantly higher complication (36.8\%) and revision (22.6\%) rates. Lastly, studies with a conflict of interest reported lower complication rates $(12.4 \%)$.

CONCLUSIONS A systematic review of the literature indicates that an axial interbody fusion performed at the lumbosacral junction is associated with a high fusion rate (93.15\%) and an acceptable complication rate (12.90\%). However, these results are based mainly on retrospective case series by authors with a conflict of interest. The limited prospective data available indicate that the actual fusion rate may be lower and the complication rate may be higher than currently reported.

http://thejns.org/doi/abs/10.3171/2015.1.SPINE14900

KEY WORDS axial interbody arthrodesis; systematic review; Axialif; L5-S1 fusion; lumbar

$\Lambda$ RTHRODESIS of the lumbosacral junction is a common surgical procedure used successfully in the treatment of multiple spinal diseases such as scoliosis and spondylolisthesis. Several techniques to fuse this segment have been described; however, an interbody technique is commonly used. This method has a large surface area for new bone formation, provides anterior column support, and can reestablish the disc height, which can both indirectly decompress the nerve roots and aid in the correction of local and global sagittal alignment..$^{13}$ While this procedure can be performed from several different approaches, each requires significant mobilization of either neurovascular structures or abdominal viscera, which can lead to significant morbidity. $6,7,12,14,22,25,28,32$

An understanding of the morbidity associated with traditional spinal exposures led to the emergence of newer minimally invasive techniques. ${ }^{20,21,23,34}$ With their newly developed instrumentation and image guidance, such tech-

ABBREVIATIONS ALIF = anterior lumbar interbody fusion; GLMM = generalized linear mixed model; rhBMP-2 = recombinant human bone morphogenetic protein 2. SUBMITTED September 2, 2014. ACCEPTED January 8, 2015.

INCLUDE WHEN CITING Published online June 12, 2015; DOI: 10.3171/2015.1.SPINE14900.

DISCLOSURE The authors report no conflict of interest concerning the materials or methods used in this study or the findings specified in this paper. Dr. Kepler is a board member of the Association of Collaborative Spine Research; is a consultant for Healthgrades Inc.; and has received support from CSRS and NASS for non-study-related clinical or research effort. Dr. Schroeder has received travel support from Medtronic. Dr. Vaccaro receives royalties from DePuy, Medtronic, Stryker Spine, Biomet Spine, Globus, and Aesculap; is a consultant for Gerson Lehrman Group, Guidepoint Global, Medacorp, Globus, Stryker Spine, Stout Medical, Innovative Surgical Design, Ellipse, Expert Testimony, Medtronic, and Orthobullets; owns stock or stock options in Globus Medical, Progressive Spinal Technologies, Advanced Spinal Intellectual Properties, Computational Biodynamics, Stout Medical, Paradigm Spine, Replication Medica, Spinology, Spine Medica, Vertiflex, Small Bone Technologies, Crosscurrent, Syndicom, In Vivo, Flagship Surgical, Location Based Intelligence, Gamma Spine, Cytonics, Bonovo Orthopaedics, Electrocore, RSI, Rothman Institute and Related Properties, Innovative Surgical Design, Flow Pharma, and Spinicity; receives research support from Cerapedics and AOSpine; receives royalties or financial support from Elsevier, Thieme, Jaypee, and Taylor \& Francis; is on the editorial board of Spine, Journal of Neurosurgery: Spine, Pan Arab Journal of Neurosurgery, and European Spine Journal; is a board member or has a committee appointment with Innovative Surgical Design, Association of Collaborative Spine Research, Spinicity, Progressive Spinal Technologies, Computational Biodynamics, Advanced Spinal Intellectual Properties, Location Based Intelligence, RSI, and Rothman Institute and Related Properties. 
niques theoretically allowed surgeons to perform similar procedures with less iatrogenic damage to surrounding soft tissues and an associated decrease in blood loss, postoperative pain, and length of hospitalization. ${ }^{20,21,23,34}$ However, these new techniques were not without problems, such as an increased risk of retrograde ejaculation with laparoscope-assisted anterior lumbar interbody fusions $(\mathrm{ALIFs})^{28}$ or inadequate restoration of foraminal height and lordosis with transforaminal interbody fusion. ${ }^{13}$

Given the aforementioned advantages of an interbody fusion at L5-S1 and the complications associated with traditional approaches, a new minimally invasive technique was designed to use the anatomical tissue plane separating

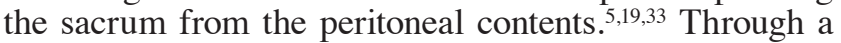
2-cm paracoccygeal incision, a cannulated drill from the sacral promontory is passed through the sacrum to create a path to the L5-S1 disc. After the discectomy and bone grafting are performed, an axial-directed cylindrical implant (AxiaLIF, Baxano Surgical) is inserted ${ }^{4,9}$ Cadaveric studies have demonstrated the biomechanical efficacy of such an implant ${ }^{1,17}$ and have further shown that the intact annulus and anterior longitudinal ligament allow for indirect decompression of the neural foramen from ligamentotaxis. ${ }^{1,17}$ Currently, the literature on the clinical application of this technique is limited almost exclusively to case series and case reports, so this systematic review was designed to answer the questions, What are the fusion rate and safety profile for an axial interbody arthrodesis of the L5-S1 motion segment?

\section{Methods}

\section{Electronic Database Search}

Two authors (G.D.S and C.K.K) independently performed a systematic MEDLINE search via PubMed for literature published between January 1, 2000, and August 17, 2014. Peer-reviewed articles related to an axial interbody arthrodesis of the lumbosacral junction were identified using combinations of the following search terms: "Axialif," "axial transsacral fusion," "axial transsacral arthrodesis," "presacral lumbar interbody fusion," "presacral lumbar interbody arthrodesis," "paracoccygeal fusion," "paracoccygeal arthrodesis," "paracoccygeal transsacral fixation," and "minimally invasive fusion of L5/S1." Only clinical studies on human subjects and in the English language were included. The reference lists of identified articles were also systematically reviewed, and any other eligible articles were incorporated. Included articles were chosen based on the inclusion and exclusion criteria listed in Table 1 . All studies in which more than $10 \%$ of a cohort met the exclusion criteria were excluded.

\section{Data Extraction}

The abstract of every identified article was reviewed, and over half of the studies were excluded based on information in the abstract alone. The remaining articles could not be unequivocally dismissed based on the abstract, so a full review of each of these articles was performed. Approximately half of these articles were eventually excluded based on the criteria in Table 1. One retrospective cohort study by Gerszten et al. compared fusion rates in patients who had undergone an axial interbody fusion of L5-S1 with or without the use of recombinant human bone morphogenetic protein 2 (rhBMP-2). ${ }^{9}$ Because all of the patients underwent an axial interbody fusion at L5S1 and because there was wide variability in the use of rhBMP-2 in other studies, the Gerszten et al. study was treated as a large case series. Only a single article comparing axial interbody fusions and another interbody fusion technique was identified. ${ }^{31}$ Because no other comparative

TABLE 1. Inclusion and exclusion criteria for studies on axial interbody fusion of the lumbosacral junction

\begin{tabular}{|c|c|c|}
\hline Study Component & Inclusion & Exclusion \\
\hline \multirow[t]{2}{*}{ Participants } & Age $\geq 18$ yrs & Age $<18$ yrs \\
\hline & $\begin{array}{l}\text { A pathology of DDD, spondylosis, spondylolisthesis, scoliosis, pseud- } \\
\text { arthrosis, revision surgery }\end{array}$ & A pathology of tumor, infection, or trauma \\
\hline Interventions & $\begin{array}{l}\text { Patients undergoing axial interbody arthrodesis of lumbosacral junc- } \\
\text { tion }\end{array}$ & \\
\hline Comparators & $\begin{array}{l}\text { Patients undergoing ALIF, posterior lumbar interbody fusion, or trans- } \\
\text { foraminal interbody fusion }\end{array}$ & \\
\hline \multirow[b]{2}{*}{ Outcomes } & L5-S1 fusion rate & $\begin{array}{l}\text { Radiographic outcomes that did not clearly define the fu- } \\
\text { sion rate at L5-S1 }\end{array}$ \\
\hline & $\begin{array}{l}\text { Complication rates: nonunion, revision surgery, infection, postop ra- } \\
\text { diculopathy, neurological deficit, bowel perforation, retroperitoneal } \\
\text { hematoma/vascular injury, hardware failure }\end{array}$ & Mean FU $<12$ mos \\
\hline \multirow{2}{*}{ Study Designs } & $\begin{array}{l}\text { Study assessing L5-S1 fusion rate after an axial interbody arthro- } \\
\text { desis of the L5-S1 segment }\end{array}$ & Nonclinical study \\
\hline & $\begin{array}{l}\text { Study assessing complications in patients with an L5-S1 fusion rate } \\
\text { utilizing an axial interbody arthrodesis }\end{array}$ & Case report \\
\hline Publication & $\begin{array}{l}\text { Study published in English in a peer-reviewed, PubMed-indexed } \\
\text { journal }\end{array}$ & $\begin{array}{l}\text { Review articles, abstracts, editorials, letters, repeat pub- } \\
\text { lication of same patient group, and study reporting the } \\
\text { technical feasibility of the surgery }\end{array}$ \\
\hline
\end{tabular}

$\mathrm{DDD}=$ degenerative disc disease; $\mathrm{FU}=$ follow-up. 
studies were identified, that single comparative article was treated as a case series, and only patients from the Axialif arm were included in our systematic review.

All reported complications were noted, including pseudarthrosis at L5-S1, revision and/or subsequent surgery, infections, postoperative radiculopathy, neurological deficits, bowel perforations, retroperitoneal hematomas and/or vascular injury, and significant medical complications (for example, myocardial infarction, stroke, and so forth). In addition to the overall incidence of complications, prospective versus retrospective studies and studies with and without a reported conflict of interest were identified. Furthermore, a level of evidence was assigned to each study using the Journal of Bone and Joint Surgery level of evidence table (http://jbjs.org/instructionsfor-authors\#LevelsofEvidence), which is an adaptation of work published from the Centre for Evidence-Based Medicine. ${ }^{17}$ Lastly, studies were identified as comprising patients with either degenerative or deformity-based spinal disease according to the surgery performed and the underlying diagnoses. Studies were included in the degenerative group if less than $20 \%$ of patients underwent surgery at 3 or more levels or had a diagnosis of high-grade spondylolisthesis or scoliosis.

\section{Statistical Analysis}

Data amassed from individual articles were analyzed using the lme4 package in the $\mathrm{R}$ statistical platform ( $\mathrm{R}$ Foundation for Statistical Computing). We performed a generalized linear mixed model (GLMM) to estimate the rate of outcomes by using conflict of interest (yes/no), prospective versus retrospective study, and degenerative versus deformity-based spinal disease as fixed effects and study as a random effect. The $\mathrm{p}$ values are based on the estimated parameter value and the standard error, and a $p$ value $<0.05$ was accepted as significant.

While we initially intended to perform a statistical analysis on the frequency of all complications, the reported number of postoperative radiculopathies, neurological deficits, bowel perforations, and retroperitoneal hematomas and/or vascular injuries was insufficient to allow for a formal analysis. We analyzed L5-S1 pseudarthrosis, all complications except for pseudarthrosis, revision and/ or subsequent surgery, and postoperative infections. Estimated complication rates (with confidence intervals), averaged across studies, were reported based on the GLMM, both per predictor and overall.

\section{Results}

We reviewed the abstract of every identified article (74; Fig. 1) and excluded 43 articles, including 20 review articles, 11 cadaveric studies, 7 non-English-language articles, and 5 articles establishing the feasibility of the procedure. The 31 remaining articles could not be unequivocally dismissed on the basis of the abstract, so each of these articles was fully reviewed. Sixteen additional articles were excluded at this time: 5 case reports, 5 articles in which the patient underwent multilevel fusions and there was no clearly reported fusion rate at L5-S1, 4 articles describing the technique but without follow-up, and 2 articles in which patients underwent lumbar fusion via multiple tech-

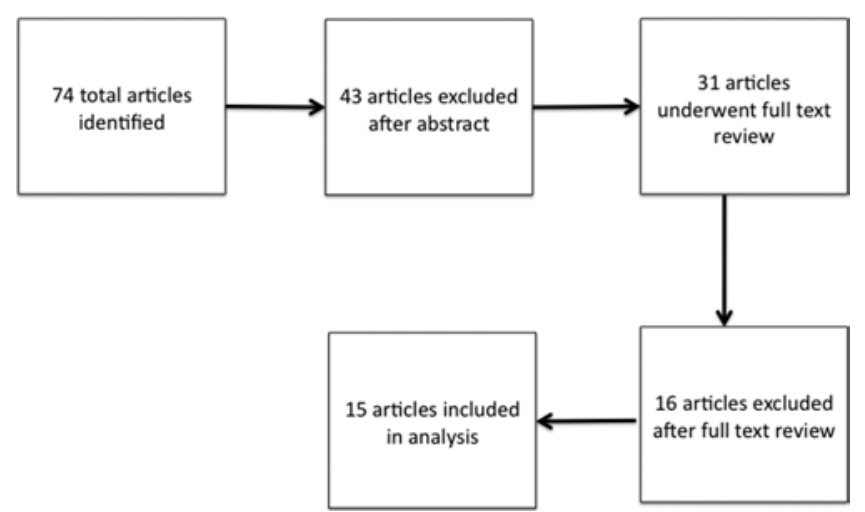

FIG. 1. Flowchart demonstrating the literature review results.

niques and there was no clearly described results of the L5-S1 axial interbody fusion.

Overall, 15 articles with 700 patients were included..$^{2-4}$, 8-11,15,18,26,27,29-31,35 Thirteen of the 15 articles were case series (Level IV evidence), ${ }^{2-4,8,10,11,15,18,26,27,29,30,35}$ and 2 were retrospective cohort studies (Level III evidence), ${ }^{9,31}$ The overall pseudarthrosis rate at L5-S1 following axial interbody arthrodesis was $6.9 \%$ (95\% CI $1.0 \%-16.2 \%)$. Failed fusion was verified by CT in 12 of the 15 studies and by radiography in the remaining 3 studies. The rate of all complications excluding pseudarthrosis was $12.9 \%$ $(4.5 \%-27.5 \%)$. A total of $14.4 \%$ of patients (range $11.3 \%-$ $20.1 \%$ ) required additional surgery, and the infection rate was $5.44 \%$ (range $2.50 \%-9.66 \%$ ). The unadjusted numbers of rare complications are listed in Table 2.

When the case series were categorized as degenerative or deformity studies, the deformity group had a significantly increased rate of complications compared with the degenerative group (46.3\% vs 9.2\%, $\mathrm{p}=0.004$; Table 3 ). Similarly, compared with retrospectively collected data, the prospectively collected data demonstrated a significantly higher complication rate $(36.8 \%$ vs $8.7 \%, \mathrm{p}=0.003)$ and a higher rate of revision surgery (22.6\% vs $12.9 \%, \mathrm{p}=$ 0.03; Table 4). Lastly, industry-sponsored studies or studies in which the authors had a conflict of interest reported lower complication rates than the studies with no conflict of interest (12.4\% vs $17.8 \%, \mathrm{p}<0.0001$; Table 5).

\section{Discussion}

The use of an interbody fusion technique for the treatment of several different diseases affecting the lumbosacral junction has been well established in the litera-

TABLE 2. Unadjusted number of rare complications

\begin{tabular}{lc}
\hline \multicolumn{1}{c}{ Complication } & $\begin{array}{c}\text { Total Reported } \\
\text { Occurrences }\end{array}$ \\
\hline Postop radiculopathy & 7 \\
\hline Broken Axialif & 3 \\
\hline Retroperitoneal hematoma/vascular injury & 2 \\
\hline Myocardial infarction & 2 \\
\hline Stroke & 2 \\
\hline Bowel perforation & 1 \\
\hline
\end{tabular}


TABLE 3. Subgroup analysis grouping studies according to type of disease

\begin{tabular}{lccc}
\hline \multicolumn{1}{c}{ Parameter } & Deformity-Based Disease & Degenerative Disease & $p$ Value \\
\hline No. of articles & 4 & 11 & \\
\hline No. of patients & 86 & 614 & 0.87 \\
\hline Pseudarthrosis & $7.08 \%(2.52 \%-18.31 \%)$ & $5.87 \%(0.73 \%-34.50 \%)$ & $0.004^{*}$ \\
\hline All complications excluding pseudarthrosis & $46.26 \%(16.21 \%-79.30 \%)$ & $9.20 \%(6.70 \%-12.50 \%)$ & 0.35 \\
\hline Revision or subsequent surgery & $28.21 \%(7.34 \%-66.30 \%)$ & $15.54 \%(12.10 \%-19.72 \%)$ & 0.06 \\
\hline All postop infections & $13.82 \%(4.95 \%-33.07 \%)$ & $4.42 \%(2.40 \%-8.02 \%)$ &
\end{tabular}

ture ${ }^{13,24,36,37}$ however, significant complications have been associated with all approaches. . $7,12,14,22,25,28,32$ Thus, a new technique using a minimally invasive paracoccygeal approach to perform axial interbody arthrodesis was developed. Our purpose in this systematic review was to determine the safety profile and fusion rate when an axial interbody technique was used for an L5-S1 arthrodesis. We found a low risk of complications and a fusion rate of $93.15 \%$. The fusion rate was not significantly affected by any of the factors in the subgroup analyses.

The fusion rates for axial interbody fusion compare favorably with those following classic techniques for a fusion at L5-S1. In a prospective, randomized multicenter study of the ProDisc-L disc replacement versus circumferential fusion, the authors reported a fusion rate of $97 \%$ at 2 years for 75 patients undergoing an ALIF. However, one-third of the fusions were performed at the more biomechanically advantageous L4-5 or L3 $-4,{ }^{36,37}$ and none of these patients were undergoing deformity surgery.

Similarly, the revision rate for axial interbody fusion is similar to that identified in the multicenter prospective, randomized, controlled investigational device exemption study of the FlexiCore artificial disc (Stryker Spine). ${ }^{24}$ Sasso et al. reported a $35 \%$ revision rate at 2 years in patients who had undergone an ALIF, and in the current study only $14.42 \%$ of patients who had undergone axial interbody fusion required a revision. Even patients in the prospective subgroup analysis $(22.56 \%)$ and the deformity analysis $(28.21 \%$ ) had revision rates less than $35 \%$.

This paper has significant limitations. Foremost, it is a systematic review of 13 case series and 2 retrospective cohort studies. No Level I or Level II studies on this technique have been published. Furthermore, only 4 available articles were prospective studies,,${ }^{8,10,28,29}$ and only 4 studies were completely independent..$^{4,10,11,29}$ Additionally, the lead author of one of the independent studies ${ }^{29}$ reported owning significant stock in TranS1 (currently Baxano Surgi- cal) in an article published 2 months later..$^{30}$ Our subgroup analyses demonstrated that the limitations of the available literature should not be trivialized, as the prospective data revealed a statistically significant increase in complications and revisions and a nonsignificant increase in the rate of pseudarthrosis.

A second limitation of this study is that multiple variables, which could not be accounted for, may have affected the fusion rate. Not only was there variation between studies in the use of posterior instrumentation, but there was also significant heterogeneity of the overall constructs within the same studies; stand-alone constructs, bilateral or unilateral pedicle screws, and facet screws were all documented to varying degrees. However, one would expect this variation to lead to inferior fusion rates, and the overall fusion rate was quite high. Similarly, the choice of bone graft and biological enhancers varied both between and within the studies. Eight studies reported the use of

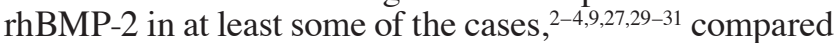
with 5 studies that reported not using rhBMP-28,11,18,26,35 and 2 cases that did not report their choice of bone graft. ${ }^{10,15}$

Lastly, this systematic review only establishes the fusion rate and safety profile of an L5-S1 axial interbody fusion. It does not address patient-reported clinical outcomes or radiographic parameters aside from fusion. Ideally, this review would have included health-related quality of life metrics; however, with significant heterogeneity in the surgical indications between as well as within studies, we believed that a meaningful interpretation of these results was not possible. One would expect a patient undergoing axial interbody fusion for spondylolisthesis with instability to have significantly improved clinical results, compared with the outcome in a patient undergoing axial interbody fusion for low-back pain and degenerative disc disease. Because there was no clear way to separate these patients, we elected not to report the clinical outcomes. Nonetheless, this information in the current study is sig-

TABLE 4. Subgroup analysis grouping studies according to type of data collection

\begin{tabular}{lccc}
\hline \multicolumn{1}{c}{ Parameter } & Prospective & Retrospective & $p$ Value \\
\hline No. of articles & 4 & 11 & \\
\hline No. of patients & 104 & 596 & 0.40 \\
\hline Pseudarthrosis & $12.09 \%(2.24 \%-45.22 \%)$ & $5.4 \%(1.88 \%-14.57 \%)$ & $0.003^{*}$ \\
\hline All complications excluding pseudarthrosis & $36.75 \%(14.35 \%-66.85 \%)$ & $8.73 \%(6.55 \%-11.56 \%)$ & $0.03^{*}$ \\
\hline Revision or subsequent surgery & $22.56 \%(14.97 \%-32.53 \%)$ & $12.92 \%(9.20 \%-17.83 \%)$ & 0.61 \\
\hline All postop infections & $3.43 \%(0.44 \%-22.09 \%)$ & $5.89 \%(3.44 \%-9.91 \%)$ &
\end{tabular}


TABLE 5. Subgroup analysis grouping studies according to conflict of interest

\begin{tabular}{lccc}
\hline \multicolumn{1}{c}{ Parameter } & Conflicts Reported & No Conflicts of Interest & $p$ Value \\
\hline No. of articles & 11 & 4 & \\
\hline No. of patients & 586 & 114 & 0.25 \\
\hline Pseudarthrosis & $5.40 \%(1.88 \%-14.57 \%)$ & $16.41 \%(2.96 \%-55.80 \%)$ & $<0.0001^{*}$ \\
\hline All complications excluding pseudarthrosis & $12.44 \%(8.20 \%-18.44 \%)$ & $17.77 \%(11.96 \%-25.58 \%$ & 0.87 \\
\hline Revision or subsequent surgery & $16.36 \%(11.87 \%-22.12 \%)$ & $17.09 \%(10.97 \%-25.66 \%)$ & 0.26 \\
\hline All postop infections & $3.79 \%(1.67 \%-8.38 \%)$ & $7.60 \%(3.38 \%-16.20 \%)$ & \\
\hline * Statistically significant. & & &
\end{tabular}

nificant: Even though the clinical outcomes of lumbar fusions vary significantly by surgical indication, it is clear that patients who develop pseudarthrosis after lumbar fusion have inferior long-term clinical results. ${ }^{16}$

This review highlights the weakness in the literature on an L5-S1 axial interbody fusion; high-level studies are required to determine how this technique can be best used. Keys for future investigators include prospective studies ideally randomizing patients to an axial interbody fusion and an alternative interbody fusion technique; non-industry-funded studies to remove any perceived author bias; and strict inclusion criteria such that included patients are only those who are undergoing lumbar fusion for an evidenced-based reason such as spondylolisthesis associated with instability.

\section{Conclusions}

A systematic review of the literature indicated that an axial interbody fusion performed at the lumbosacral junction is associated with a high fusion rate $(93.15 \%)$ and an acceptable complication rate $(12.90 \%)$. However, these results are based mainly on retrospective case series by authors with a conflict of interest, and the limited prospective data available indicate that the actual fusion rate may be lower and the complication rate may be higher than currently reported.

\section{References}

1. Akesen B, Wu C, Mehbod AA, Transfeldt EE: Biomechanical evaluation of paracoccygeal transsacral fixation. J Spinal Disord Tech 21:39-44, 2008

2. Anand N, Baron EM, Khandehroo B: Does minimally invasive transsacral fixation provide anterior column support in adult scoliosis? Clin Orthop Relat Res 472:1769-1775, 2014

3. Anand N, Rosemann R, Khalsa B, Baron EM: Mid-term to long-term clinical and functional outcomes of minimally invasive correction and fusion for adults with scoliosis. Neurosurg Focus 28(3):E6, 2010

4. Aryan HE, Newman CB, Gold JJ, Acosta FL Jr, Coover C, Ames CP: Percutaneous axial lumbar interbody fusion (AxiaLIF) of the L5-S1 segment: initial clinical and radiographic experience. Minim Invasive Neurosurg 51:225-230, 2008

5. Cragg A, Carl A, Casteneda F, Dickman C, Guterman L, Oliveira C: New percutaneous access method for minimally invasive anterior lumbosacral surgery. J Spinal Disord Tech 17:21-28, 2004

6. Cummock MD, Vanni S, Levi AD, Yu Y, Wang MY: An analysis of postoperative thigh symptoms after minimally invasive transpsoas lumbar interbody fusion. J Neurosurg Spine 15:11-18, 2011
7. Elias WJ, Simmons NE, Kaptain GJ, Chadduck JB, Whitehill R: Complications of posterior lumbar interbody fusion when using a titanium threaded cage device. J Neurosurg 93 (1 Suppl):45-52, 2000

8. Gerszten PC, Tobler W, Raley TJ, Miller LE, Block JE, Nasca RJ: Axial presacral lumbar interbody fusion and percutaneous posterior fixation for stabilization of lumbosacral isthmic spondylolisthesis. J Spinal Disord Tech 25:E36E40, 2012

9. Gerszten PC, Tobler WD, Nasca RJ: Retrospective analysis of L5-S1 axial lumbar interbody fusion (AxiaLIF): a comparison with and without the use of recombinant human bone morphogenetic protein-2. Spine J 11:1027-1032, 2011

10. Hadjipavlou A, Alpantaki K, Katonis P, Vastardis G, Tzermiadianos M, Benardos N: Safety and effectiveness of retrorectal presacral approach for lumbosacral axial instrumentation. A clinical study. Acta Orthop Belg 79:222-229, 2013

11. Hofstetter CP, Shin B, Tsiouris AJ, Elowitz E, Härtl R: Radiographic and clinical outcome after 1- and 2-level transsacral axial interbody fusion. Clinical article. J Neurosurg Spine 19:454-463, 2013

12. Houten JK, Alexandre LC, Nasser R, Wollowick AL: Nerve injury during the transpsoas approach for lumbar fusion. $\mathbf{J}$ Neurosurg Spine 15:280-284, 2011

13. Hsieh PC, Koski TR, O’Shaughnessy BA, Sugrue P, Salehi S, Ondra S, et al: Anterior lumbar interbody fusion in comparison with transforaminal lumbar interbody fusion: implications for the restoration of foraminal height, local disc angle, lumbar lordosis, and sagittal balance. J Neurosurg Spine 7:379-386, 2007

14. Humphreys SC, Hodges SD, Patwardhan AG, Eck JC, Murphy RB, Covington LA: Comparison of posterior and transforaminal approaches to lumbar interbody fusion. Spine (Phila Pa 1976) 26:567-571, 2001

15. Issack PS, Boachie-Adjei O: Axial lumbosacral interbody fusion appears safe as a method to obtain lumbosacral arthrodesis distal to long fusion constructs. HSS J 8:116-121, 2012

16. Kornblum MB, Fischgrund JS, Herkowitz HN, Abraham DA, Berkower DL, Ditkoff JS: Degenerative lumbar spondylolisthesis with spinal stenosis: a prospective long-term study comparing fusion and pseudarthrosis. Spine (Phila Pa 1976) 29:726-734, 2004

17. Ledet EH, Tymeson MP, Salerno S, Carl AL, Cragg A: Biomechanical evaluation of a novel lumbosacral axial fixation device. J Biomech Eng 127:929-933, 2005

18. Marchi L, Oliveira L, Coutinho E, Pimenta L: Results and complications after 2-level axial lumbar interbody fusion with a minimum 2-year follow-up. J Neurosurg Spine 17:187-192, 2012

19. Marotta N, Cosar M, Pimenta L, Khoo LT: A novel minimally invasive presacral approach and instrumentation technique for anterior L5-S1 intervertebral discectomy and fusion: technical description and case presentations. Neurosurg Focus 20(1):E9, 2006

20. Park Y, Ha JW: Comparison of one-level posterior lumbar 
interbody fusion performed with a minimally invasive approach or a traditional open approach. Spine (Phila Pa 1976) 32:537-543, 2007

21. Peng CW, Yue WM, Poh SY, Yeo W, Tan SB: Clinical and radiological outcomes of minimally invasive versus open transforaminal lumbar interbody fusion. Spine (Phila Pa 1976) 34:1385-1389, 2009

22. Rajaraman V, Vingan R, Roth P, Heary RF, Conklin L, Jacobs GB: Visceral and vascular complications resulting from anterior lumbar interbody fusion. J Neurosurg 91 (1 Suppl):60-64, 1999

23. Regan JJ, Yuan H, McAfee PC: Laparoscopic fusion of the lumbar spine: minimally invasive spine surgery. A prospective multicenter study evaluating open and laparoscopic lumbar fusion. Spine (Phila Pa 1976) 24:402-411, 1999

24. Sasso RC, Foulk DM, Hahn M: Prospective, randomized trial of metal-on-metal artificial lumbar disc replacement: initial results for treatment of discogenic pain. Spine (Phila Pa 1976) 33:123-131, 2008

25. Scaduto AA, Gamradt SC, Yu WD, Huang J, Delamarter RB, Wang JC: Perioperative complications of threaded cylindrical lumbar interbody fusion devices: anterior versus posterior approach. J Spinal Disord Tech 16:502-507, 2003

26. Shedid D, Weil AG, Lieberman I: A novel minimally invasive technique for the treatment of high-grade isthmic spondylolisthesis using a posterior transsacral rod. J Spinal Disord Tech 27:E41-E48, 2014

27. Tender GC, Miller LE, Block JE: Percutaneous pedicle screw reduction and axial presacral lumbar interbody fusion for treatment of lumbosacral spondylolisthesis: A case series. J Med Case Reports 5:454, 2011

28. Than KD, Wang AC, Rahman SU, Wilson TJ, Valdivia JM, Park P, et al: Complication avoidance and management in anterior lumbar interbody fusion. Neurosurg Focus 31(4):E6, 2011

29. Tobler WD, Ferrara LA: The presacral retroperitoneal approach for axial lumbar interbody fusion: a prospective study of clinical outcomes, complications and fusion rates at a follow-up of two years in 26 patients. J Bone Joint Surg Br 93:955-960, 2011

30. Tobler WD, Gerszten PC, Bradley WD, Raley TJ, Nasca RJ, Block JE: Minimally invasive axial presacral L5-S1 interbody fusion: two-year clinical and radiographic outcomes. Spine (Phila Pa 1976) 36:E1296-E1301, 2011

31. Whang PG, Sasso RC, Patel VV, Ali RM, Fischgrund JS: Comparison of axial and anterior interbody fusions of the
L5-S1 segment: a retrospective cohort analysis. J Spinal Disord Tech 26:437-443, 2013

32. Wood KB, Devine J, Fischer D, Dettori JR, Janssen M: Vascular injury in elective anterior lumbosacral surgery. Spine (Phila Pa 1976) 35 (9 Suppl):S66-S75, 2010

33. Yuan PS, Day TF, Albert TJ, Morrison WB, Pimenta L, Cragg A, et al: Anatomy of the percutaneous presacral space for a novel fusion technique. J Spinal Disord Tech 19:237241,2006

34. Zdeblick TA, David SM: A prospective comparison of surgical approach for anterior L4-L5 fusion: laparoscopic versus mini anterior lumbar interbody fusion. Spine (Phila Pa 1976) 25:2682-2687, 2000

35. Zeilstra DJ, Miller LE, Block JE: Axial lumbar interbody fusion: a 6-year single-center experience. Clin Interv Aging 8:1063-1069, 2013

36. Zigler J, Delamarter R, Spivak JM, Linovitz RJ, Danielson GO III, Haider TT, et al: Results of the prospective, randomized, multicenter Food and Drug Administration investigational device exemption study of the ProDisc-L total disc replacement versus circumferential fusion for the treatment of 1-level degenerative disc disease. Spine (Phila Pa 1976) 32:1155-1163, 2007

37. Zigler JE, Delamarter RB: Five-year results of the prospective, randomized, multicenter, Food and Drug Administration investigational device exemption study of the ProDisc-L total disc replacement versus circumferential arthrodesis for the treatment of single-level degenerative disc disease. J Neurosurg Spine 17:493-501, 2012

\section{Author Contributions}

Conception and design: Vaccaro. Acquisition of data: Schroeder, Kepler. Analysis and interpretation of data: Schroeder. Drafting the article: Schroeder. Critically revising the article: Kepler, Vaccaro. Reviewed submitted version of manuscript: Kepler, Vaccaro. Administrative/technical/material support: Vaccaro. Study supervision: Vaccaro.

\section{Correspondence}

Gregory D. Schroeder, The Rothman Institute at Thomas Jefferson University, 1015 Walnut St., Curtis Building, Rm. 509, Philadelphia, PA 19107. email: gregdschroeder@gmail.com. 